\title{
ESTABLISHING THE RELIABILITY OF THE TESTIMONY OF MINORS IN THE COURSE OF FORENSIC PSYCHOLOGICAL EXAMINATION
}

\author{
Olga E. Andrushchenko \\ Volgograd State University, Volgograd, Russian Federation \\ Vadim N. Perekrestov \\ Judicial District No. 47, Svetly Yar, Volgograd Region, Russian Federation
}

\begin{abstract}
Introduction: the paper analyzes the problems of developing the criteria for establishing the reliability of the testimony of minors in the performance of forensic psychological examination. In search of these criteria, the authors discuss the existing theoretical and methodological approaches to the study of the credibility of the minor victims, the offenders and witnesses; analyze the legal aspects of forensic psychological examination of the testimony of persons under age, for their validity and reliability. Using the method of scientific knowledge, first of all comparative law, the official statistics of the investigative actions involving minors participating in the criminal proceedings in different status are analyzed. In addition, the paper uses the formal logical method. Results: the features of minors that determine the procedure for performing expert examination, including the specifics of the child's personality and the level of its psychological and intellectual development, emotional state, are identified. Conclusions: the analyzed specific excerpts from the conclusions of the expert examinations allowed us to identify the criteria for the reliability of the testimony of minors and analyze the specifics of the experts' approaches to this procedure.
\end{abstract}

Key words: minor, forensic psychological examination, reliability, validity, testimony.

Citation. Andrushchenko O.E., Perekrestov V.N. Establishing the Reliability of the Testimony of Minors in the Course of Forensic Psychological Examination. Legal Concept, 2020, vol. 19, no. 2, pp. 71-76. (in Russian). DOI: https://doi.org/10.15688/lc.jvolsu.2020.2.10

УДК 343.140.02:343.955

Дата поступления: 13.03.2020

ББК 67.53 Дата принятия: 05.04.2020

\section{УСТАНОВЛЕНИЕ ДОСТОВЕРНОСТИ ПОКАЗАНИЙ НЕСОВЕРШЕННОЛЕТНИХ В ХОДЕ ПРОИЗВОДСТВА СУДЕБНО-ПСИХОЛОГИЧЕСКОЙ ЭКСПЕРТИЗЫ}

\author{
Ольга Евгеньевна Андрющенко \\ Волгоградский государственный университет, г. Волгоград, Российская Федерация \\ Вадим Николаевич Перекрестов \\ Судебный участок № 47, р. п. Светлый Яр, Волгоградская область, Российская Федерация
}

Введение: в статье анализируются проблемы разработки критериев установления достоверности показаний несовершеннолетних в процессе производства судебно-психологической экспертизы. С целью поиска данных критериев в работе автором рассматриваются существующие теоретико-методологические подходы к исследованию достоверности показаний несовершеннолетних жертв, участников преступлений и 
свидетелей; проанализированы правовые аспекты судебно-психологической экспертизы показаний лиц, не достигших совершеннолетнего возраста, на предмет их надежности и достоверности. С помощью метода научного познания, прежде всего сравнительного правоведения, проанализирована официальная статистика следственных действий с участием несовершеннолетних участников уголовного процесса в различном статусе. Кроме того, в работе использован формально-логический метод. Результаты: выявлены особенности несовершеннолетнего возраста, обусловливающие процедуру производства судебно-психологической экспертизы, среди которых специфика личности ребенка и уровень ее психологического и интеллектуального развития, эмоциональное состояние. Выводы: проанализированные конкретные выдержки из заключений экспертиз позволили выявить критерии достоверности показаний несовершеннолетних и проанализировать специфику подходов экспертов к данной процедуре.

Ключевые слова: несовершеннолетний, судебно-психологическая экспертиза, достоверность, надежность, показания.

Цитирование. Андрющенко О. Е., Перекрестов В. Н. Установление достоверности показаний несовершеннолетних в ходе производства судебно-психологической экспертизы // Legal Concept = Правовая парадигма. - 2020. - T. 19, № 2. - С. 71-76. -DOI: https://doi.org/10.15688/lc.jvolsu.2020.2.10

\section{Введение}

В последнее время в России актуализируется необходимость научного осмысления проблем участия детей в уголовном процессе. Очевидно, что допрос несовершеннолетних подозреваемых, обвиняемых, свидетелей и потерпевших имеет свою специфику в силу возраста и социально-психологического статуса допрашиваемых. Необходимость производства данного следственного действия с участием несовершеннолетних участников уголовного процесса обусловлена ростом количества преступлений, совершаемых в отношении детей: с 69,6 тыс. деяний в 2016 г. до 96,1 тыс. в 2018 г; увеличением количества преступлений, совершенных членами семьи против несовершеннолетних (2018 г. - 54697 преступлений; 2017 г. - 44568 преступлений; 2016 г. 23448 преступлений) [1]. Кроме того, практически неизменным остается удельный вес преступлений, совершенных несовершеннолетними или при их соучастии, в общей структуре преступности, - на уровне 4-4,5 \% за тот же период.

Судебно-психологическая экспертиза (далее - СПЭ) представляет собой вид судебной экспертизы, применяемой в следственно-судебной деятельности с привлечением психологов для выработки заключения, позволяющего подтвердить доказательную базу по уголовному делу [6]. Важно отметить, что СПЭ назначается в отношении лиц, чье психическое здоровье не вызывает сомнений. Проведение СПЭ позволяет решить несколь- ко важных задач: понять и корректно оценить значимые для правовых выводов особенности психической деятельности конкретных лиц; оценить вызывающие сомнения показания потерпевших, свидетелей, подозреваемых, обвиняемых и подсудимых на предмет достоверности. Кроме того, в ходе производства СПЭ выявляется возможность допрашиваемого лица адекватно воспринимать, запоминать и воспроизводить сведения о фактах, подлежащих доказыванию, с учетом индивидуальных особенностей протекания его психических процессов.

\section{Специфика \\ судебно-психологической экспертизы}

Расследование преступлений с участием несовершеннолетних либо в отношении них имеет целый ряд особенностей, обусловленных их правовым статусом: так, в одном случае ребенок нуждается в защите после перенесенной травмы, в другом случае необходимо обеспечить адекватное наказание, но в том и другом - с непременным учетом его личностных характеристик и качеств.

В настоящее время применяется три вида судебно-психологической экспертизы несовершеннолетних: 1) если несовершеннолетний нарушил чьи-либо права (оценке подлежат его психологические особенности и риски повторного совершения противоправного деяния); 2) если он пострадал от чьих-либо действий (оцениваются психологические особенности и состояние ребенка); 3) если он 
является свидетелем преступления (оцениваются психологические особенности ребенка и дается психологический анализ показаний).

В каждом конкретном деле возможность допроса зависит от уровня развития несовершеннолетнего и от характера обстоятельств дела, по поводу которых он должен быть опрошен. Так, к случаям, при которых назначается СПЭ с участием несовершеннолетних, следует отнести:

1. Необходимость установить способность несовершеннолетнего в полном объеме осознавать опасность своих действий и управлять ими, если он имеет отставание непсихического характера.

2. Необходимость определить способность несовершеннолетнего участника преступления правильно воспринимать ситуации и давать о них корректные сведения.

3. При расследовании преступлений, связанных с нарушением половой неприкосновенности несовершеннолетнего, необходимость установить, способен ли ребенок понимать, какое значение имеют действия, произведенные в отношении него и мог ли он оказать сопротивление.

Следует отметить, что в Уголовно-процессуальном кодексе РФ закреплен перечень условий, которые необходимо соблюдать в ходе расследования преступления, совершенного несовершеннолетним: во-первых, установить особенности личности, уровень его психологического и интеллектуального развития, а вовторых, при наличии отставания необходимо выявить уровень осознания опасности совершаемых / несовершаемых действий и возможность управлять ими. При этом проблема участия детей с ограниченными возможностями здоровья в уголовном судопроизводстве остается практически не изученной.

Характерной отличительной чертой представителей несовершеннолетнего возраста при даче показания является искажение или изменение сведений, что затрудняет предварительное расследование, так как ребенок не несет ответственности за дачу заведомо ложных показаний. В данном случае привлекают экспертов-психологов на предмет выявления склонности к фантазии, конфабуляциям, внушению. Возрастные особенности несовершеннолетнего, степень его глубоких психоло- гических переживаний, физиологические изменения, модель семейного воспитания, гендерные особенности - тот комплекс факторов, который необходимо учитывать специалистам при проведении СПЭ. Отказ от проведения экспертизы с большей долей вероятности приведет к невосполнимой утрате доказательств, преступление останется нераскрытым, а виновные лица избегут заслуженного наказания. Таким образом, установление достоверности показаний несовершеннолетних участников уголовного производства является крайне важным условием.

Однако в научной литературе долгое время велись дискуссии об уголовно-процессуальных и криминалистических аспектах участия несовершеннолетних в уголовном процессе в различном качестве. Преобладающее количество работ было и остается посвящено исследованию и совершенствованию тактических рекомендаций по взаимодействию в ходе уголовного процесса с несовершеннолетними участниками. Напротив, в незначительном количестве научных трудов освещена эволюция законодательного регулирования участия несовершеннолетних в сфере уголовного судопроизводства.

\section{Отечественные и зарубежные теоретические подходы к анализу достоверности показаний несовершеннолетних}

Достоверность показаний является критерием использования показаний несовершеннолетних лиц. Одна из существовавших точек зрения базируется на утверждении, что ложь и фантазия характерна для всех детей, в связи с чем невозможно использовать детские показания, поскольку они не несут доказательной ценности. Такой подход ранжирует показания несовершеннолетних в зависимости от возраста: показания малолетних детей практически недостоверны по сравнению с показаниями детей старшего возраста. Отдельные ученые придерживались радикального отрицательного подхода к показаниям несовершеннолетних [5], вплоть до выработки категоричного мнения о невозможности использования детских показаний в уголовном судопроизводстве [11]. 
В рамках другого подхода также отмечается необходимость строгого ранжирования показаний несовершеннолетних лиц по возрастным признакам. Более того, детские показания могут являться даже более ценными, чем взрослые, при условии зрелости комплекса психических функций и познавательных процессов, прежде всего, памяти [2]. Например, отмечалось, что показания детей нельзя считать достоверными, если они носят описательный характер [4]. В рамках данной позиции было исследовано влияние наводящих вопросов на качество и точность показаний несовершеннолетних [4], подверженность детей ко внушению со стороны взрослых и самовнушению [7], склонность несовершеннолетних подавлять воспоминания о психотравмирующих фактах [4].

Наконец, в рамках третьего подхода допрос несовершеннолетних рассматривается как процессуальное действие [8]. Б.М. Шавер отмечал, что несовершеннолетнее лицо - не некая абстракция, а конкретная личность с индивидуальными качествами, способная воспринимать события, в связи с чем иметь определенное отношение к фактам и давать показания. Разделяя данный подход, М.С. Строгович изучал фантазии, выдуманные несуществующие обстоятельства в показаниях несовершеннолетних свидетелей, указывая на большую наблюдательность детей по сравнению со взрослыми. При этом он отмечал необходимость проверки показаний несовершеннолетних другими доказательствами [9].

Очевидно, что обойтись без допроса несовершеннолетних в ходе расследования бывает невозможно, в связи с чем вопрос о психологической достоверности свидетельских показаний приобретает особую актуальность.

Зарубежная практика производства судебно-психологических экспертиз достоверности свидетельских показаний несовершеннолетних включает в себя, помимо формальных разделов, подробный анамнез когнитивных функций ребенка; анализ полученных показаний по материалам уголовного дела; описание результатов экспериментально-психологического обследования, протокол беседы эксперта с несовершеннолетним по событиям уголовного дела, психологический анализ его показаний с учетом психологической характеристики [3].
В отечественной юридической психологии доминирует мнение, что оценка достоверности показаний несовершеннолетних в совокупности с другими доказательствами является исключительной компетенцией суда. Такой подход ограничивает задачи СПЭ содействием следственным и судебным органам в правильной оценке свидетельских показаний (оценка способности воспринимать важные обстоятельства), где ее предметом не могут являться оценка достоверности и надежности свидетельских показаний, причины изменения показаний, мотивы отказа от дачи показаний. «Оценка показаний (их полноты, достоверности, соответствия другим материалам дела) является исключительной прерогативой судебно-следственных органов» ... «экспертиза направлена исключительно на субъекта, дающего показания, а не на его показания» [8]. На наш взгляд, совершенно справедливо мнение о том, что эксперт-психолог указывает на возможные связи между психологическими особенностями лица и достоверностью показаний, исключая анализ самих свидетельских показаний на предмет надежности и достоверности.

С точки зрения такого подхода к цели СПЭ особый интерес вызывает специфика восприятия, закономерности запоминания и воспроизведения событий несовершеннолетними, влияющие на полноту, корректность и достоверность показаний. Соответственно, эксперту необходимо выявить критерии и факторы, свидетельствующие за и против «правдивости» показаний: логичность, последовательность, наличие противоречий, эмоциональная окраска, систематизация, четкость, свобода речи и т. д.

Следует отметить, что существуют и процедурные особенности проведения СПЭ несовершеннолетних. Так, ее рекомендуется проводить на первых этапах дела, поскольку результаты являются определяющими для дальнейшего хода судебно-следственных действий. Более того, при проведении СПЭ становится возможным выявить весь спектр позитивных и негативных черт личности несовершеннолетнего, уровень нервно-психической возбудимости, заторможенности, нейротизма, эмоциональной напряженности, эгоцентризм, нарциссизм, тревожность. Анализу подвергается и невербаль- 
ное поведение несовершеннолетнего, которое практически не контролируется им.

В качестве примера рассмотрим психологическую судебную экспертизу, проведенную по уголовному делу о систематическом нарушении половой неприкосновенности малолетней T., в рамках которой ей приходилось воспроизводить события 6-4-летней давности. Так, перед экспертами были поставлены вопросы о том, страдает ли несовершеннолетняя Т. какими-либо психическими заболеваниями, способна ли она давать правильные показания с учетом ее индивидуально-психологических особенностей, способна ли была оказывать сопротивление, имеются ли у нее признаки внушаемости, подчиненности, фантазирования, заученности, могла ли она осознавать характер совершаемых с нею действий.

В заключении комиссии экспертов в качестве психологических признаков достоверности показаний несовершеннолетней T. указаны такие, как «логичность описания основных событий», «детальность событий, о которых можно узнать непосредственно от потерпевшей», «связь описания событий со второстепенными обстоятельствами», «отсутствие нарушений памяти, восприятия, внимания и мышления, а также индивидуально-психологических особенностей». Данная оценка дана не только на момент экспертизы, но и относительно временного периода, в который совершались преступные действия в отношении нее.

В заключении другой судебно-психологической экспертизы по подобному уголовному делу о нарушении половой неприкосновенности несовершеннолетней И. эксперты отмечали следующие признаки недостоверности показаний: «неспособность выражать свои переживания», «отсутствие стыдливости при описании событий», «склонность к фантазированию», «внушаемость».

\section{Выводы}

Таким образом, специфика судебно-психологической экспертизы несовершеннолетних обусловлена ее задачами, решение которых позволяет: оценить особенности психической деятельности конкретных лиц и вызывающие сомнения показания потерпевших, свидетелей, подозреваемых, обвиняемых и подсудимых на предмет достоверности. В качестве психологических индикаторов достоверности / недостоверности показаний несовершеннолетних эксперты используют такие критерии, как отсутствие нарушений высших психических функций и способностей к познавательной деятельности, морально-нравственные переживания, детальность описания основных и второстепенных событий, внушаемость, фантазирование, речевые обороты и конструкции, невербальные жесты.

\section{СПИСОК ЛИТЕРАТУРЫ}

1. Государственный доклад о положении детей и семей, имеющих детей, в Российской Федерации за 2018 год // Министерство труда и социальной защиты РФ. - Электрон. текстовые дан. - Режим доступа: https://rosmintrud.ru/docs/1361 (дата обращения: 15.12.2019). - Загл. с экрана.

2. Гросс, Г. Руководство для судебных следователей как система криминалистики / Г. Гросс. М. : ЛексЭст, 2002. - 1088 с.

3. Королева, А. А. Особенности судебнопсихологической экспертизы несовершеннолетних / А. А. Королева // Развитие юридической науки и проблема преодоления пробелов в праве : сб. науч. ст. по итогам работы десятого междунар. круглого стола. - Шахты : Конверт, 2019. - С. 102-104.

4. Курланд, М. Как улучшить память / М. Курланд, Р. А. Лупоф. - М. : АСТ : Астрель, 2005. -400 с.

5. Лобзин, М. Свидетельские показания детей дошкольного возраста и отношение их к действительности / М. Лобзин // Проблемы психологии. 2012. - № 1.

6. Национальная психологическая энциклопедия. - Электрон. текстовые дан. - Режим доступа: https://vocabulary.ru/termin/ekspertiza-sudebnopsihologicheskaja.html (дата обращения: 20.11.2019). Загл. с экрана.

7. Ратинов, А. Р. Экспериментальные исследования в психологии свидетельских показаний (вопросы методики) / А. Р. Ратинов, Н. И. Гаврилова // Вопросы борьбы с преступностью. 2014. - Вып. 27. - С. 71-90.

8. Ситковская, О. Д. Психология свидетельских показаний / О. Д. Ситковская. -М. : [б. и.], 2002. - 57 с.

9. Строгонович, М. С. Об оправдании ввиду недоказанности участия подсудимого в совершении преступления / М. С. Строгонович // Правоведение. - 1983. - № 5. - С. 45-52.

10. Шавер, Б. М. Допрос несовершеннолетних / Б. М. Шавер // Социалистическая законность. 1938. - № 10. - C. 31-42. 
11. Якимов, И. Н. Допрос: Практическое пособие для допрашивающих / И. Н. Якимов, П. П. Михеев. - М. : Изд-во Народного Комиссариата Внутренних Дел, 1930. - 84 с.

\section{REFERENCES}

1. Gosudarstvennyy doklad o polozhenii detey i semey, imeyushchikh detey, $v$ Rossiyskoy Federatsii za 2018 [State Report on the Situation of Children and Families with Children in the Russian Federation for 2018]. URL: https://rosmintrud.ru/docs/1361 (accessed 15 February 2020).

2. Gross G. Rukovodstvo dlya sudebnykh sledovateley kak sistema kriminalistiki [Guide for Forensic Investigators as a System of Criminalistics]. Moscow, LeksEst, 2002. 1088 p.

3. Koroleva A.A. Osobennosti sudebnopsihologicheskoy ekspertizy nesovershennoletnikh [Features of Forensic Psychological Examination of Minors]. Razvitie yuridicheskoy nauki i problema preodoleniya probelov v prave : Sbornik Nauchnykh statey po itogam raboty desyatogo mezhdunarodnogo kruglogo stola [Development of Legal Science and the Problem of Overcoming Gaps in Law. Collection of Scientific Articles on the $10^{\text {th }}$ International Round Table], 2019, pp. 102-104.

4. Kurland M., Lupof R.A. Kak uluchshit pamyat [How to Improve Memory]. Moscow, AST Publ., Astrel Publ., 2005. 400 p.
5. Lobzin M. Svidetelskie pokazaniya detey doshkolnogo vozrasta i otnoshenie ikh k deystvitelnosti [Testimonies of Preschool Children and Their Relation to Reality]. Problemy psihologii [Problems of Psyhology], 2012, no. 1.

6. Natsionalnaya psihologicheskaya entsiklopediya [National Psychological Encyclopedia]. URL: https://vocabulary.ru/termin/ ekspertiza-sudebno-psihologicheskaja.html (accessed 17 February 2020).

7. Ratinov A.R., Gavrilova N.I. Eksperimentalnye issledovaniya $\mathrm{v}$ psikhologii svidetelskikh pokazaniy (voprosy metodiki) [Experimental Research in the Psychology of Testimony (Questions of Methodology)]. Voprosy borby s prestupnostyu [Issues of Combating Crime], 2014, vol. 27, pp. 71-90.

8. Sitkovskaya O.D. Psikhologiya svidetelskikh pokazaniy [Psychology of Testimony]. Moscow, 2002. 57 p.

9. Strogonovich M.S. Ob opravdanii vvidu nedokazannosti uchastiya podsudimogo $\mathrm{v}$ sovershenii prestupleniya [About Acquittal Due to Unproven Participation of the Defendant in the Commission of a Crime]. Pravovedenie [Jurisprudence], 1983, no. 5, pp. 45-52.

10. Shaver B.M. Dopros nesovershennoletnikh [Interrogation of Minors]. Sotsialisticheskaya zakonnost [Socialist Legality], 1938, no. 10, pp. 31-42.

11. Yakimov I.N., Miheev P.P. Dopros: Prakticheskoe posobie dlya doprashivayushchikh [Interrogation: a Practical Guide for Interrogators]. Moscow, 1930. 84 p.

\section{Information About the Authors}

Olga E. Andrushchenko, Candidate of Sciences (Jurisprudence), Associate Professor, Department of Criminal Procedure and Criminalistics, Volgograd State University, Prosp. Universitetsky, 100, 400062 Volgograd, Russian Federation, andryushchenko@volsu.ru, https://orcid.org/0000-0003-4619-160X

Vadim N. Perekrestov, Candidate of Sciences (Jurisprudence), Justice of the Peace, Judicial District No. 47, Sovetskaya St., 67, 404171 Svetly Yar, Volgograd Region, Russian Federation, bulvar04@mail.ru, https://orcid.org/0000-0003-3978-5389

\section{Информация об авторах}

Ольга Евгеньевна Андрющенко, кандидат социологических наук, доцент кафедры уголовного процесса и криминалистики, Волгоградский государственный университет, просп. Университетский, 100, 400062 г. Волгоград, Российская Федерация, andryushchenko@volsu.ru, https://orcid.org/0000-0003-4619-160X

Вадим Николаевич Перекрестов, кандидат юридических наук, мировой судья судебного участка № 47 Волгоградской области, ул. Советская, 67, 404171 п. Светлый Яр, Волгоградская область, Российская Федерация, bulvar04@mail.ru, https://orcid.org/0000-0003-3978-5389 